\title{
Trauma and psychotic experiences: transnational data from the World Mental Health Survey
}

\author{
John J. McGrath, Sukanta Saha, Carmen C. W. Lim, Sergio Aguilar-Gaxiola, Jordi Alonso, \\ Laura H. Andrade, Evelyn J. Bromet, Ronny Bruffaerts, José M. Caldas de Almeida, Graça Cardoso, \\ Giovanni de Girolamo, John Fayyad, Silvia Florescu, Oye Gureje, Josep M. Haro, Norito Kawakami, \\ Karestan C. Koenen, Viviane Kovess-Masfety, Sing Lee, Jean-Pierre Lepine, Katie A. McLaughlin, \\ Maria E. Medina-Mora, Fernando Navarro-Mateu, Akin Ojagbemi, Jose Posada-Villa, Nancy Sampson, \\ Kate M. Scott, Hisateru Tachimori, Margreet ten Have, Kenneth S. Kendler, Ronald C. Kessler, on behalf \\ of the WHO World Mental Health Survey Collaborators*
}

\section{Background}

Traumatic events are associated with increased risk of psychotic experiences, but it is unclear whether this association is explained by mental disorders prior to psychotic experience onset

\section{Aims}

To investigate the associations between traumatic events and subsequent psychotic experience onset after adjusting for post-traumatic stress disorder and other mental disorders.

\section{Method}

We assessed 29 traumatic event types and psychotic experiences from the World Mental Health surveys and examined the associations of traumatic events with subsequent psychotic experience onset with and without adjustments for mental disorders.

\section{Results}

Respondents with any traumatic events had three times the odds of other respondents of subsequently developing psychotic experiences (OR $=3.1,95 \% \mathrm{Cl}$ 2.7-3.7), with variability in strength of association across traumatic event types. These associations persisted after adjustment for mental disorders.

\section{Conclusions}

Exposure to traumatic events predicts subsequent onset of psychotic experiences even after adjusting for comorbid mental disorders.

\section{Declaration of interest}

In the past 3 years, R.C.K. received support for his epidemiological studies from Sanofi Aventis, was a consultant for Johnson \& Johnson Wellness and Prevention, and served on an advisory board for the Johnson \& Johnson Services Inc Lake Nona Life Project. He is a co-owner of DataStat, Inc, a market research firm that carries out healthcare research.

\section{Copyright and usage}

(c) The Royal College of Psychiatrists 2017.
Extensive evidence indicates that exposure to childhood trauma or other adversities is associated with increased risk of subsequent psychotic experiences. ${ }^{1}$ In a recent analysis of data from the World Health Organization (WHO) World Mental Health (WMH) surveys, McGrath et $a l^{2}$ found that childhood adversities, such as sexual or physical abuse, were associated with increased risks of subsequent psychotic experiences even after adjustment for lifetime comorbid mental disorders. Exposure to traumatic events later in life has also been linked to increased risk of subsequent psychotic experiences. Cross-sectional ${ }^{3}$ and longitudinal $^{4,5}$ studies have found especially high psychotic experience risk associated with traumatic events involving interpersonal violence. ${ }^{6,7}$ There is also evidence of a dose-response relationship between number of traumatic events and risk of subsequent psychotic experiences. ${ }^{6,8}$ However, many traumatic events are predicted by prior mental disorders and associated with an increased risk of subsequent mental disorders, most notably post-traumatic stress disorder (PTSD). ${ }^{9-11}$ We recently demonstrated that the associations of psychotic experiences with mental disorders (including PTSD) are often bidirectional. ${ }^{12}$ Thus, it seems reasonable to hypothesise that the associations of traumatic events with subsequent onset of psychotic experiences might be influenced by comorbid mental disorders. ${ }^{13}$ This could be true either because lifetime mental disorders with onsets prior to traumatic events are associated both with increased risk of

*See Appendix for list of collaborators. subsequent traumatic event exposure (such as bipolar disorder associated with increased risk of interpersonal violence, attentiondeficit hyperactivity disorder (ADHD) associated with increased risk of motor vehicle collisions) and because traumatic events are associated with increased risk of subsequent mental disorders (both PTSD and other disorders). The main aim of this study was to examine the associations of type and number of traumatic events with the subsequent onset of psychotic experiences across $16 \mathrm{WMH}$ countries and to evaluate the extent to which these associations were explained statistically by PTSD and other mental disorders.

\section{Method}

\section{Samples}

The WMH surveys are a coordinated set of community epidemiological surveys administered in probability samples of the non-institutionalised civilian household population in countries throughout the world (www.hcp.med.harvard.edu/ $\mathrm{WMH}) .{ }^{14}$ We examined data from $16 \mathrm{WMH}$ surveys that included both a psychosis module and items related to trauma exposure. These 16 countries are distributed across North and South America (Colombia, Mexico, Peru, Brazil, USA); Africa (Nigeria); the Middle East (Lebanon); the South Pacific (New Zealand) and Europe (Belgium, France, Germany, Italy, The Netherlands, Portugal, Romania, Spain). The majority of these surveys were based on multistage, clustered area probability household 
sampling designs, the exceptions being Belgium, Germany and Italy, which used municipal resident registries to select respondents (online Table DS1). The weighted (by sample size) average response rate across all 16 surveys was $70.5 \%$.

In keeping with previous studies of psychotic experiences, ${ }^{2,6,12}$ we made the a priori decision to exclude individuals reporting psychotic experiences who screened positive for possible schizophrenia/psychosis and manic depression/mania (i.e. respondents who were either told by a doctor that their psychotic experiences were caused by these conditions or who were treated with antipsychotic medications for these symptoms). This resulted in excluding 130 respondents ( $0.5 \%$ of all respondents), leaving 24464 respondents for this study (online Table DS1).

\section{Procedures}

All WMH interviews were conducted face-to-face by trained lay interviewers in the homes of respondents. Informed consent was obtained before beginning the interview. Procedures for obtaining informed consent and data protection (ethical approvals) were reviewed and approved by the institutional review boards of the collaborating organisations in each country. ${ }^{15}$ Standardised interviewer training and quality control procedures were used consistently in the surveys. All WMH interviews had two parts. Part I, administered to all respondents, contained assessments related to core mental disorders (depression, mania, panic disorder, social phobia, specific phobia, agoraphobia, generalised anxiety disorder, substance use). Part II, which included other mental disorders, traumatic events and psychotic experiences, was administered to respondents who met lifetime criteria for any part I disorder and a random proportion of the rest. Respondents in the part II sample were weighted by the inverse of their probability of selection to restore representativeness. Additional weights were used to adjust for differential probabilities of selection within households, non-response and to match the samples to population sociodemographic distributions. ${ }^{15}$

\section{Data collection and data items}

The instrument used in the WMH surveys was the WHO Composite International Diagnostic Interview (CIDI), ${ }^{15}$ a validated fully structured diagnostic interview (https://www.hcp.med.harvard. edu/wmhcidi/download-the-who-wmh-cidi-instruments/) designed to assess the prevalence and correlates of a wide range of mental disorders according to the definitions and criteria of both the DSM-IV and ICD-10 diagnostic systems. ${ }^{16,17}$ DSM-IV criteria are used in the current report. WHO translation, back-translation and harmonisation protocols were used to adapt the CIDI for use in each participating country.

\section{Psychotic experiences}

The psychosis module included questions about six psychotic experience types - two related to hallucinatory experiences and four related to delusional experiences (online Tables DS2, DS3). The respondents were asked if they ever experienced each psychotic experience (for example 'Have you ever seen something that wasn't there that other people could not see?'; 'Have you ever heard any voices that other people said did not exist?' etc.). Only psychotic experiences occurring when the person was 'not dreaming, not half-asleep, or not under the influence of alcohol or drugs' were included. For those with psychotic experiences, age at onset of psychotic experiences was also assessed.

\section{Mental disorders}

The WMH version of the CIDI assessed lifetime history of 21 mental disorders including mood disorders, anxiety disorders, behaviour disorders, eating disorder, and substance use disorders (online Table DS4). Clinical reappraisal studies indicate that lifetime diagnoses based on the CIDI have good concordance with diagnoses based on masked clinical interviews. ${ }^{18}$

\section{Traumatic experiences}

The CIDI assessed 29 traumatic events that have been broadly classified into six categories. Details of these categories have been published elsewhere. ${ }^{19}$ These categories are: (a) collective violence (civilian in a war zone, refugee, civilian in region of terror, kidnapped, and relief worker in war zone); (b) caused/witnessed bodily harm (purposely injured, tortured, or killed someone, combat experience, accidentally caused serious injury or death, saw atrocities, and witnessed death/dead body or saw someone seriously hurt); (c) interpersonal violence (beaten up by caregiver, witnessed physical fight at home, and beaten up by someone else); (d) intimate partner/sexual violence (raped, sexually assaulted, beaten up by spouse/romantic partner, stalked, traumatic event to loved one, private event, and some other event); (e) accidents/ injuries (child with serious illness, natural disaster, life-threatening illness, toxic chemical exposure, other life-threatening accident, and automobile accident); and (f) other traumas (unexpected death of a loved one, mugged or threatened with a weapon, and man-made disaster). Information on age at first exposure associated with each traumatic event was also collected. Of note, this study extends our previous report on the subset of traumatic events that occurred in childhood ${ }^{2}$ by evaluating the impact of traumatic events occurring across the lifespan.

\section{Statistical analysis}

Lifetime prevalence of each traumatic event was calculated using cross-tabulation. Discrete-time survival analysis with person-year as the unit of analysis was used to investigate the associations of exposure to traumatic events with the subsequent first onset of psychotic experiences. A person-year data-set was created such that each year in the life of each respondent (up to and including the age at onset of psychotic experience or their age at interview, whichever came first) was treated as a separate observational record. In all analyses the year of psychotic experience onset was coded as 1 and earlier years coded as 0 on a dichotomous outcome variable. Traumatic events were coded as 1 only beginning the year after the onset of traumatic events to ensure that we were not including onsets of traumatic event and psychotic experience occurring in the same year or traumatic events occurring after psychotic experience onset. We estimated 29 bivariate models (i.e. considering only 1 traumatic event type out of 29 types at a time) in predicting psychotic experiences adjusting for age-cohort, gender, person-year dummy variables, and country. We then estimated a series of multivariate models: (a) model 1 included all traumatic events simultaneously as predictors without considering the number of traumatic events (type model); (b) model 2 included number of traumatic events coded as dummy variables (exactly 1 , exactly $2, \ldots, 5$ or more traumatic events) without any information on type of traumatic events (number model); (c) model 3 included both type and number of traumatic events (simple interactive model); and (d) model 4 included type and number of traumatic events along with a separate interaction term between each type and each number of other co-occurring traumatic events (complex interactive model). The latter models showed the 'marginal effects' of each type of traumatic event, where a marginal effect is the 'partial derivative effect' (a unique contribution) of a specific traumatic event to psychotic experiences while the contribution from all other traumatic events remains constant. Owing to the co-occurring nature of traumatic 
events, it is difficult to fractionate the impact of individual traumatic events on psychotic experiences using models 1-3. While model 3 assumed simple interactions, model 4 allowed each type of traumatic event to vary in slope as a function of number of co-occurring traumatic events. The model with the best fit to the data according to the Akaike information criterion (AIC) was carried forward into subsequent examination of the extent to which associations of traumatic events with subsequent psychotic experiences changed when we adjusted for history of PTSD (model 5 ) and also other temporally prior (to the psychotic experience) mental disorders (model 6).

As the WMH data are both clustered and weighted, the design-based Taylor series linearisation implemented in SUDAAN software was used to estimate standard errors and evaluate the statistical significance of coefficients. Survival coefficients were exponentiated and reported as odds ratios. All significance tests were evaluated using 0.05 -level two-sided tests.

\section{Results}

\section{Prevalence of traumatic events in those with and without psychotic experiences}

Of the 24464 respondents, more than two-thirds ( $n=18535$, $71.8 \%$ ) reported exposure to at least one traumatic event in their lifetime (online Table DS5). The lifetime prevalence of traumatic event exposure among respondents with psychotic experiences was $90.4 \%$ compared with $70.5 \%$ in those with no psychotic experiences. Among respondents with psychotic experiences, there was a wide variation in the frequency of exposure to specific types of traumatic events, with the highest prevalence reported for unexpected death of a loved one $(45.6 \%)$ followed by witnessed death or saw someone seriously hurt $(41.8 \%)$, and mugged or threatened with weapon $(29.9 \%)$. In this sample, more than three-quarters $(75.8 \%)$ of the traumatic events occurred before the onset of psychotic experiences, whereas only 19.2\% occurred after psychotic experience onset $\left(\chi^{2}{ }_{1}=337.3, P<0.001\right)$ (online Table DS5).

\section{The associations of type and number of traumatic events with psychotic experiences}

Tables 1 and 2 summarise the bivariate and multivariable associations of type and number of traumatic events with subsequent first onset of psychotic experiences. Overall, respondents with any traumatic event had threefold increased odds of subsequent onset of psychotic experiences $(\mathrm{OR}=3.1,95 \%$ CI 2.7-3.7) compared with respondents with no traumatic events. In the bivariate models, all but three traumatic event types (civilian in war zone or region of terror, and relief worker in war zone) were significantly associated with elevated odds of subsequent psychotic experiences. The significant odds ratios ranged between 1.6 and 3.5 with the highest being associated with rape ( $\mathrm{OR}=3.5,95 \% \mathrm{CI} 2.7-4.4)$, and the lowest with unexpected death of a loved one $(\mathrm{OR}=1.6,95 \% \mathrm{CI}$ $1.4-1.9)$ and natural disaster $(\mathrm{OR}=1.6,95 \%$ CI 1.2-2.1).

In model 1, which adjusted for all traumatic events types, 13 of the 29 traumatic event types were significantly associated with onset of psychotic experiences, with odds ratios ranging from $0.3(95 \% \mathrm{CI}=0.1-0.8)$ for relief worker in a war zone to 2.0 $(95 \% \mathrm{CI}=1.0-3.8)$ for being a refugee. As a set, traumatic events were significantly associated with psychotic experiences $\left(\chi_{29}^{2}=745.7, P<0.001\right)$, and there was significant variation in the magnitude of associations across traumatic events $\left(\chi_{28}^{2}=71.7, P<0.001\right)$. With respect to the number of traumatic events (Table 2, model 2), a dose-response relationship between traumatic events and psychotic experiences, was evident with the odds ratios increasing monotonically as exposure to traumatic events increased $\left(\chi^{2}{ }_{5}=355.9, P<0.001\right)$.

In model 3, which adjusted for both type and number of traumatic events, 12 traumatic events were significantly associated with psychotic experiences: 10 with increased odds of subsequent psychotic experiences whereas two traumatic events ('relief worker in war zone', 'civilian in war zone') were protective with respect to subsequent psychotic experience onset. The odds ratio associated with number of traumatic events were consistently elevated and in the range 1.7-1.3 (Table 2, model 3), indicating that the relative odds of subsequently having psychotic experiences among respondents with more than one prior traumatic event were between 1.7 and 1.3 times the relative odds implied by multiplying together the marginal odds ratios. For example, a respondent who had been exposed to beaten by caregiver, raped, sexually assaulted, and an automobile accident would have an expected odds ratio of subsequent psychotic experiences of 5.0 compared with someone with no traumatic event exposure (i.e. $1.6 \times 1.6 \times 1.5 \times 1.3)$. Given that the number of possible traumatic event interaction combinations $\left(2^{29}-30=536870911\right)$ greatly exceeded the number of observations, model 3 makes the simplifying assumption that the odds ratios describing interactions are identical for all co-occurring traumatic events involving the same number of traumatic events. However, we found that the test for variation in odds ratios was significant $\left(\chi_{28}^{2}=64.6, P<0.001\right)$, indicating variation across traumatic event types in the interaction of traumatic event type and number of other traumatic events in predicting psychotic experiences. Thus, we next evaluated a more complex interactive model (model 4) that considered distinct interactions for specific traumatic events together with number of other co-occurring traumatic events.

Table 3 presents a set of complex interactive models with both type and number of traumatic events (model 4 ) as well as models adjusted for mental disorders (models 5 and 6). Twelve traumatic events were significantly associated with psychotic experience onset in the 'marginal effects' models. Interestingly, several traumatic events showed stronger associations with psychotic experience in this model. For example, those who endorsed 'raped' had about fivefold increased odds of subsequent onset of psychotic experiences (OR $=4.9,95 \%$ CI 2.5-9.5). The 'marginal effect' for number of traumatic events was significant $\left(\chi^{2}{ }_{1}=5.1\right.$, $P=0.024)$. The result shows that for every one-unit increment of number of traumatic events, we expect a $10 \%$ increase in the odds of subsequent onset of psychotic experiences regardless of the type of traumatic events (OR $=1.1,95 \%$ CI $1.0-1.3$ ).

When we adjusted for PTSD (model 5), the pattern of findings (effect size, direction, and significance) remained remarkably similar. When we adjusted for all mental disorders assessed in the surveys (model 6, including PTSD), 11 of the 29 traumatic events were significantly associated with psychotic experiences. The patterns were generally consistent although for a handful of traumatic events, the odds ratios were slightly attenuated. Overall, these results indicate that the significant associations of specific traumatic events with onset of psychotic experiences were not explained by prior (to the psychotic experiences) mental disorders.

\section{Discussion}

\section{Main findings}

Based on a large data-set from 16 countries, we confirmed that traumatic events are associated with a threefold increased odds of subsequent first onset of psychotic experiences. There was a dose-response relationship between higher numbers of traumatic event types and odds of psychotic experiences. The findings are 
Table 1 Bivariate and multivariate associations of temporally prior traumatic experiences with subsequent onset of psychotic experiences

\begin{tabular}{|c|c|c|c|}
\hline Type of traumatic experiences & $\begin{array}{l}\text { Bivariate models }{ }^{a} \\
\quad \text { OR }(95 \% \mathrm{Cl})\end{array}$ & $\begin{array}{l}\text { M1 - Multivariate type model } \\
\text { OR }(95 \% \mathrm{Cl})\end{array}$ & $\begin{array}{c}\text { M3 - Multivariate simple } \\
\text { interactive model }^{\mathrm{C}} \\
\text { OR }(95 \% \mathrm{Cl})\end{array}$ \\
\hline \multicolumn{4}{|l|}{ Collective violence } \\
\hline Civilian in war zone & $1.0(0.6-1.5)$ & $0.7(0.4-1.0)$ & $0.6 *(0.4-1.0)$ \\
\hline Refugee & $2.0 *(1.1-3.6)$ & $2.0 *(1.0-3.8)$ & $1.8(0.9-3.5)$ \\
\hline Civilian in region of terror & $1.6(1.0-2.6)$ & $1.2(0.7-2.0)$ & $1.1(0.7-1.9)$ \\
\hline Kidnapped & $2.3^{*}(1.5-3.7)$ & $1.0(0.6-1.6)$ & $1.0(0.6-1.6)$ \\
\hline Relief worker in war zone & $0.6(0.3-1.6)$ & $0.3^{*}(0.1-0.8)$ & $0.3^{*}(0.1-0.9)$ \\
\hline \multicolumn{4}{|l|}{ Caused/witnessed bodily harm } \\
\hline Purposely injured, tortured or killed someone & $2.7^{*}(1.3-5.4)$ & $1.1(0.5-2.4)$ & $1.1(0.5-2.5)$ \\
\hline Combat experience & $1.8 *(1.1-3.0)$ & $1.3(0.8-2.2)$ & $1.3(0.8-2.1)$ \\
\hline Accidentally caused serious injury or death & $3.1^{*}(2.2-4.5)$ & $1.6 *(1.1-2.3)$ & $1.6 *(1.1-2.3)$ \\
\hline Saw atrocities & $1.7^{*}(1.2-2.4)$ & $0.9(0.6-1.3)$ & $0.9(0.7-1.4)$ \\
\hline \multicolumn{4}{|l|}{$\begin{array}{l}\text { Witnessed death/dead body or saw someone } \\
\text { seriously hurt }\end{array}$} \\
\hline \multicolumn{4}{|l|}{ Interpersonal violence } \\
\hline Beaten up by caregiver & $2.6^{*}(2.2-3.1)$ & $1.7 *(1.4-2.1)$ & $1.6^{*}(1.3-1.9)$ \\
\hline Witnessed physical fight at home & $2.1 *(1.8-2.4)$ & $1.2 *(1.0-1.5)$ & $1.1(1.0-1.4)$ \\
\hline Beaten up by someone else & $2.1 *(1.6-2.7)$ & $1.0(0.8-1.3)$ & $1.0(0.8-1.4)$ \\
\hline \multicolumn{4}{|l|}{ Intimate partner/sexual violence } \\
\hline Raped & $3.5^{*}(2.7-4.4)$ & $1.7^{*}(1.2-2.3)$ & $1.6^{*}(1.2-2.3)$ \\
\hline Sexually assaulted & $2.7^{*}(2.2-3.3)$ & $1.5^{\star}(1.2-2.0)$ & $1.5^{\star}(1.1-1.9)$ \\
\hline Beaten up by spouse/romantic partner & $2.4^{*}(1.9-3.1)$ & $1.2(0.9-1.6)$ & $1.3(1.0-1.6)$ \\
\hline Stalked & $2.4^{*}(1.9-3.1)$ & $1.2(0.9-1.6)$ & $1.2(0.9-1.6)$ \\
\hline Traumatic event to loved one & $2.6 *(2.1-3.3)$ & $1.3^{*}(1.0-1.7)$ & $1.4^{*}(1.1-1.8)$ \\
\hline Private event & $2.5^{*}(1.9-3.3)$ & $1.5^{\star}(1.1-2.0)$ & $1.5^{\star}(1.1-2.0)$ \\
\hline Some other event & $1.9 *(1.4-2.7)$ & $1.3(0.9-1.8)$ & $1.3(0.9-1.8)$ \\
\hline \multicolumn{4}{|l|}{ Accident/injuries } \\
\hline Child with serious illness & $2.2^{*}(1.6-3.1)$ & $1.6^{*}(1.1-2.2)$ & $1.5^{\star}(1.1-2.1)$ \\
\hline Natural disaster & $1.6 *(1.2-2.1)$ & $1.1(0.8-1.5)$ & $1.1(0.8-1.4)$ \\
\hline Life-threatening illness & $1.7^{*}(1.3-2.0)$ & $1.2(1.0-1.5)$ & $1.2(0.9-1.4)$ \\
\hline Toxic chemical exposure & $2.4^{*}(1.7-3.3)$ & $1.5^{*}(1.1-2.2)$ & $1.5^{\star}(1.1-2.1)$ \\
\hline Other life threatening accident & $2.0 *(1.5-2.6)$ & $1.2(0.9-1.6)$ & $1.2(0.9-1.6)$ \\
\hline Automobile accident & $2.1 *(1.7-2.5)$ & $1.4 *(1.1-1.7)$ & $1.3^{*}(1.1-1.6)$ \\
\hline \multicolumn{4}{|l|}{ Other traumas } \\
\hline Unexpected death of a loved one & $1.6 *(1.4-1.9)$ & $1.1(1.0-1.3)$ & $1.1(0.9-1.3)$ \\
\hline Mugged or threatened with a weapon & $2.0 *(1.6-2.5)$ & $1.3(1.0-1.6)$ & $1.2(0.9-1.6)$ \\
\hline Man-made disaster & $1.8 *(1.3-2.5)$ & $1.0(0.7-1.4)$ & $1.0(0.7-1.4)$ \\
\hline Any traumatic events & $3.1 *(2.7-3.7)$ & NA & NA \\
\hline Joint significance of all 29 traumatic events, $\chi^{2}$ (d.f.) $P$ & NA & $745.7 *(29) P<0.001$ & $128.4^{*}(29) P<0.001$ \\
\hline Differences in the ORs of the 29 traumatic events, $\chi^{2}$ (d.f.) $P$ & NA & $71.7 *(29) P<0.001$ & $64.6 *(28) P<0.001$ \\
\hline \multicolumn{4}{|c|}{$\begin{array}{l}\text { NA, not applicable } \\
\text { a. Each lifetime traumatic event type was used as a predictor of psychotic experiences onset in separate discrete-time survival model controlling for age-cohorts, gender, } \\
\text { person-year dummies, and country } \\
\text { b. Model was estimated with dummy variables for all temporally prior traumatic events entered simultaneously including the controls specified above } \\
\text { c. Model was estimated with dummy variables for type and number of traumatic events (starting at } 2 \text { traumatic events, } 3 \text { traumatic events, ..., } 5 \text { or more traumatic events) entered } \\
\text { simultaneously as predictors of psychotic experiences onset including the controls specified in (a) } \\
{ }^{*} P<0.05,2 \text {-sided test }\end{array}$} \\
\hline
\end{tabular}

Table 2 Associations between number of temporally prior traumatic experiences and the subsequent onset of psychotic experiences

\begin{tabular}{|c|c|c|}
\hline & $\begin{array}{c}\text { M2 - Multivariate number model } \\
\text { OR }(95 \% \mathrm{Cl})\end{array}$ & $\begin{array}{c}\text { M3 - Multivariate simple interactive } \text { model }^{\text {b }} \\
\text { OR }(95 \% \mathrm{CI})\end{array}$ \\
\hline 1 traumatic event & $2.3^{*}(1.9-2.8)$ & - \\
\hline 2 traumatic events & $3.5^{*}(2.8-4.4)$ & $1.7^{*}(1.4-2.1)$ \\
\hline 3 traumatic events & $4.0 *(3.1-5.1)$ & $1.5^{*}(1.1-2.0)$ \\
\hline 4 traumatic events & $5.0 *(3.8-6.7)$ & $1.5^{*}(1.1-2.2)$ \\
\hline 5 or more traumatic events & $7.6 *(6.1-9.5)$ & $1.3(0.8-2.1)$ \\
\hline \multicolumn{3}{|c|}{ Joint significance of number-of-traumatic } \\
\hline \multicolumn{3}{|c|}{$\begin{array}{l}\text { aModel was estimated with dummy variables for all number of traumatic events without any information about type of traumatic events entered simultaneously controlling for } \\
\text { age-cohorts, gender, person-year dummies, and country } \\
\text { b Model was estimated with dummy variables for type and number of traumatic events (starting at } 2 \text { traumatic events, } 3 \text { traumatic events, . .,5 or more traumatic events) entered } \\
\text { simultaneously as predictors of psychotic experiences onset including the controls specified in (a). } \\
{ }^{*} P<0.05,2 \text {-sided test. }\end{array}$} \\
\hline
\end{tabular}




\begin{tabular}{|c|c|c|c|}
\hline Type of traumatic experiences ${ }^{a}$ & $\begin{array}{l}\text { Model } 4 \text { - multivariate complex } \\
\text { interactive } \text { model }^{\mathrm{b}}\end{array}$ & $\begin{array}{c}\text { Model } 5 \\
\text { (adjusted for PTSD) }^{\mathrm{c}}\end{array}$ & $\begin{array}{l}\text { Model } 6 \text { (adjusted for } \\
\text { mental disorders) }\end{array}$ \\
\hline \multicolumn{4}{|l|}{ Collective violence, marginal effects OR $(95 \% \mathrm{Cl})$} \\
\hline Civilian in war zone & $0.4(0.1-1.0)$ & $0.4(0.1-1.0)$ & $0.4^{\star}(0.1-1.0)$ \\
\hline Refugee & $3.0(0.8-11.0)$ & $2.9(0.8-10.7)$ & $2.9(0.8-10.3)$ \\
\hline Civilian in region of terror & $2.5(0.6-9.8)$ & $2.5(0.6-9.8)$ & $2.4(0.6-9.6)$ \\
\hline Kidnapped & $1.3(0.3-5.7)$ & $1.3(0.3-5.7)$ & $1.2(0.2-5.7)$ \\
\hline \multicolumn{4}{|l|}{ Caused/witnessed bodily harm, marginal effects OR (95\% Cl) } \\
\hline Combat experience & $1.2(0.2-5.7)$ & $1.1(0.2-5.7)$ & $1.2(0.2-5.9)$ \\
\hline Accidentally caused serious injury or death & $2.3(0.7-7.7)$ & $2.3(0.7-7.7)$ & $1.7(0.6-4.5)$ \\
\hline Saw atrocities & $1.5(0.5-4.7)$ & $1.5(0.5-4.7)$ & $1.5(0.5-4.6)$ \\
\hline Witnessed death/dead body or saw someone seriously hurt & $1.9 *(1.4-2.5)$ & $1.9 *(1.4-2.5)$ & $1.8^{*}(1.3-2.5)$ \\
\hline \multicolumn{4}{|l|}{ Interpersonal violence, marginal effects OR (95\% Cl) } \\
\hline Beaten up by caregiver & $2.0 *(1.4-2.9)$ & $2.0 *(1.4-2.8)$ & $1.9 *(1.3-2.7)$ \\
\hline Witnessed physical fight at home & $1.8 *(1.4-2.3)$ & $1.8 *(1.4-2.3)$ & $1.8^{*}(1.4-2.3)$ \\
\hline Beaten up by someone else & $1.9(0.9-4.2)$ & $1.9(0.9-4.2)$ & $1.8(0.8-3.9)$ \\
\hline \multicolumn{4}{|l|}{ Intimate partner/sexual violence, marginal effects OR $(95 \% \mathrm{Cl})$} \\
\hline Raped & $4.9 *(2.5-9.5)$ & $4.8 *(2.5-9.5)$ & $4.3^{*}(2.2-8.4)$ \\
\hline Sexually assaulted & $2.2^{*}(1.4-3.6)$ & $2.2^{\star}(1.3-3.5)$ & $2.0 *(1.3-3.3)$ \\
\hline Beaten up by spouse/romantic partner & $1.4(0.8-2.6)$ & $1.4(0.8-2.6)$ & $1.3(0.7-2.3)$ \\
\hline Stalked & $3.4^{*}(2.0-5.6)$ & $3.4^{*}(2.0-5.6)$ & $3.0 *(1.8-5.0)$ \\
\hline Traumatic event to loved one & $2.0 *(1.1-3.5)$ & $2.0 *(1.1-3.5)$ & $1.8^{*}(1.0-3.3)$ \\
\hline Private event & $2.0(0.9-4.5)$ & $2.0(0.9-4.5)$ & $1.9(0.9-4.2)$ \\
\hline Some other event & $1.5(0.7-3.1)$ & $1.5(0.7-3.1)$ & $1.4(0.7-2.9)$ \\
\hline \multicolumn{4}{|l|}{ Accident/injuries, marginal effects OR $(95 \% \mathrm{Cl})$} \\
\hline Child with serious illness & $1.8(0.7-4.5)$ & $1.8(0.7-4.5)$ & $1.9(0.8-4.6)$ \\
\hline Natural disaster & $1.2(0.7-2.0)$ & $1.2(0.7-2.0)$ & $1.2(0.7-1.9)$ \\
\hline Life-threatening illness & $1.5^{*}(1.0-2.3)$ & $1.5^{\star}(1.0-2.3)$ & $1.5(1.0-2.3)$ \\
\hline Toxic chemical exposure & $1.5(0.7-3.4)$ & $1.5(0.7-3.4)$ & $1.5(0.7-3.2)$ \\
\hline Other life-threatening accident & $2.1 *(1.3-3.4)$ & $2.1 *(1.3-3.4)$ & $2.0 *(1.3-3.3)$ \\
\hline Automobile accident & $2.0 *(1.4-3.0)$ & $2.0 *(1.4-3.0)$ & $2.0 *(1.3-2.9)$ \\
\hline \multicolumn{4}{|l|}{ Other traumas, marginal effects OR $(95 \% \mathrm{Cl})$} \\
\hline Unexpected death of a loved one & $1.5^{\star}(1.1-2.0)$ & $1.5^{*}(1.1-2.0)$ & $1.5^{*}(1.1-2.0)$ \\
\hline Mugged or threatened with a weapon & $1.9 *(1.1-3.5)$ & $1.9 *(1.1-3.5)$ & $1.8(1.0-3.3)$ \\
\hline Man-made disaster & $1.2(0.5-2.8)$ & $1.2(0.5-2.8)$ & $1.2(0.5-2.9)$ \\
\hline Joint significance of all traumatic events, $\chi^{2}$ (d.f.) $P$ & $140.9 *(29)<0.001$ & $139.9 *(29)<0.001$ & $118.2^{*}(29)<0.001$ \\
\hline \multicolumn{4}{|l|}{ Number of other co-occurring traumatic events } \\
\hline Marginal effects OR $(95 \% \mathrm{Cl})$ & $1.1 *(1.0-1.3)$ & $1.1 *(1.0-1.3)$ & $1.1^{\star}(1.0-1.3)$ \\
\hline$\chi^{2}$ (d.f.) $P$ & $5.1 *(1) 0.024$ & $5.2^{*}(1) 0.023$ & $5.2^{*}(1) 0.023$ \\
\hline \multicolumn{4}{|c|}{$\begin{array}{l}\text { a. The traumatic events: 'Relief worker in war zone' and 'Purposely injured, tortured, or killed someone' are not included in the table as the results are not applicable because of } \\
\text { unstable estimates. Total person-years used for this multivariate model is } 1041109 \text {. } \\
\text { b. Complex interactive model was estimated with dummy variables for type and number of temporally prior traumatic events and interaction terms for each type of traumatic event } \\
\text { and number of other traumatic events including the controls: age-cohorts, gender, person-year dummies, and country. } \\
\text { c. Model specification in (b) and additionally control for temporally prior post-traumatic stress disorder (PTSD) only. } \\
\text { d. Model specification in (b) and additionally control for } 21 \text { temporally prior and intervening mental disorders (PTSD inclusive). } \\
{ }^{*} P<0.05,2 \text {-sided test. }\end{array}$} \\
\hline
\end{tabular}

consistent with recent literature that traumatic events are associated with psychotic experiences in a dose-dependent fashion. ${ }^{3-6,8}$ In addition, the study contributed two important findings: first, traumatic events were not equipotent with respect to the subsequent first onset of psychotic experiences. Second, comorbid mental disorders (including PTSD) did not account for the associations of traumatic events with psychotic experiences.

\section{Variation in the strength of association}

With respect to the variation in the strength of association across traumatic event types, prior research has often failed to use statistical models that adequately address the intercorrelated nature of traumatic events. We constructed multivariable models that included a comprehensive list of 29 traumatic event types, and incorporated number of traumatic events per person, as well as interactive models. Similar to our earlier analysis of childhood adversities and psychotic experience onsets, ${ }^{2}$ we found that not all traumatic events had equivalent associations with subsequent first onset of psychotic experiences. For example, in the marginal effect model (model 4), we found that only 12 of the 29 traumatic event types were associated with an increased risk of subsequent psychotic experiences. Six of the ten traumatic events related to interpersonal violence, intimate partner, and sexual violence were associated with psychotic experiences (effect sizes ranged from 1.8 to 4.9 for 'witnessed physical fight at home' and 'raped', respectively). Those who endorsed 'raped' had fivefold increased odds of subsequent onset of psychotic experiences $(\mathrm{OR}=4.9$, 95\% CI 2.5-9.5). The general pattern of findings indicates a complex interactive association between traumatic event types and number of traumatic events. In the complex interactive model (model 4), we also found that those who were exposed to more traumatic events were more likely to develop a first-onset psychotic experience regardless of type of traumatic events. This is consistent with the hypothesis that traumatic event exposure is a risk factor for psychosis, ${ }^{20}$ and also lends additional support for the 
important role of stress in aetiological pathways underpinning risk of psychotic experiences. Interestingly, in some models, 'civilian or relief worker in war zone' showed protective effects with respect to subsequent psychotic experiences onset. This is consistent with previous WMH survey studies with traumatic events, which suggest that respondents who had war experience may have a reduced risk of mental or physical disorders compared with the general population. ${ }^{21}$ This may partly be because of a selection effect and/or to prior exposure promoting resilience. ${ }^{21}$ In summary, the nature of the relationship between exposure to traumatic events and subsequent psychotic experiences is more nuanced than previously thought.

\section{Role of comorbid disorders}

With respect to the explanatory effects of comorbid disorders, we found that the associations of traumatic events with psychotic experiences were mostly unchanged after adjustment for mental disorders that began prior to the onset of psychotic experiences. This adjustment included both confounding effects (i.e. mental disorders that both predicted subsequent occurrence of traumatic events and later onset of psychotic experiences) and mediating effects (i.e. traumatic events predicting subsequent onset of mental disorders that, in turn, are predictors of later psychotic experiences). No attempt was made to distinguish between the two types of effects. The finding that comorbid mental disorders do not account for the associations of traumatic events with subsequent psychotic experiences is consistent with our earlier findings that there was little or no influence of mental disorders on the associations of childhood adversities with psychotic experiences. ${ }^{2}$ In particular, we found that PTSD did not appear to play a substantial role in accounting for the associations of traumatic events with psychotic experiences. This was in contrast to an earlier finding, where those with both exposure to traumatic events and associated PTSD were at greater risk of lifetime psychotic experiences. ${ }^{8}$ However, our finding is consistent with the hypothesis that some (but not all) traumatic events may be 'sufficient' causes of subsequent psychotic experience onset (i.e. an intervening mental disorder is not required to trigger psychotic experiences). Of course, genetic factors and other unmeasured confounders could influence this association.

Even though the exact mechanisms linking traumatic events to psychotic experiences remain poorly understood, there is considerable recent interest in how socially mediated factors and traumatic events may influence the aetiology of psychotic experiences. Traumatic events may create a constitutional disposition for psychotic experiences that may include heightened vulnerability to stress, ${ }^{22}$ elevated emotional reactivity and dysregulation ${ }^{21,23}$ and deficits in cognitive control. ${ }^{24}$ For example, it is feasible that psychopathology emerges as the end product of distress and anxiety because of maladaptive stress and emotional reactions of traumatic events, which in turn may lead to dopamine sensitisation. These pathways may influence psychosis vulnerability. ${ }^{25}$ Stress-related changes in the hypopituitary axis could also have an impact on brain circuitry via epigenetic mechanisms, leading to vulnerability to subsequent psychotic experiences. ${ }^{26}$

\section{Limitations}

Although the current study has many strengths (for example range of traumatic event types, large sample size, range of countries, uniform methodology for data collection), it also has several limitations that deserve comment. We excluded those who screened positive for possible psychotic disorders based on selfreporting having received a psychosis diagnosis or having used antipsychotic medications to treat the reported psychotic experiences. However, it is possible that some respondents who reported psychotic experiences had an untreated psychotic disorder. We also relied on retrospective reports about age at onset, which might have led to a recall bias. However, we note that several prospective studies have confirmed the association between traumatic events and subsequent psychotic experiences. ${ }^{4,5}$ Although we had age at exposure for each type of traumatic event, we could not define the pattern of exposure across the life course (for example we could not identify those who only had childhood exposure $v$. those that had both childhood and adult exposure). We failed to control for all plausible correlates of both traumatic event exposure and psychotic experiences, as we wanted to focus on comorbid mental disorders and we were concerned that other plausible correlates (such as socioeconomic status and education) could be either causes or consequences of both traumatic event exposure and psychotic experiences. Finally, while our findings are consistent with the hypothesis that particular types of traumatic event exposure may contribute to the development of subsequent psychotic experiences, the surveys are cross-sectional and thus unable to determine causal pathways.

\section{Implications}

Despite these limitations, our study found that many of the traumatic events (11 out of 29) were independently associated with subsequent psychotic experiences in a large, communitybased transnational study that were not mediated by mental disorders. The robust literature now linking traumatic events and subsequent psychotic experiences may enrich the epidemiological landscape of psychotic experiences, and can provide important clues to the aetiology and pathogenesis of psychotic experiences.

\section{Funding}

The World Health Organization World Mental Health (WMH) Survey Initiative is supported by the National Institute of Mental Health (NIMH; R01 MH070884), the John D. and Catherine MacArthur Foundation, the Pfizer Foundation, the US Public Health Service (R13-MH066849 R01-MH069864, and R01 DA016558), the Fogarty International Center (FIRCA R03Tw006481), the Pan American Health Organization, Eli Lilly and Company, Ortho-McNeil Pharmaceutical, GlaxoSmithKline, and Bristol-Myers Squibb. None of the funders had any role in the design, analysis, interpretation of results, or preparation of this paper. The views and opinions expressed in this report are those of the authors and should not be construed to represent the views of the World Health Organization, other sponsoring organisations, agencies, or governments.

The Colombian National Study of Mental Health (NSMH) is supported by the Ministry of Social Protection. The ESEMeD project is funded by the European commission (Contracts QLG5-1999-01042; SANCO 2004123, and EAHC 20081308), the Piedmont Region (Italy)), Fondo de Investigación Sanitaria, Instituto de Salud Carlos III, Spain (FIS 00/0028), Ministerio de Ciencia y Tecnología, Spain (SAF 2000-158-CE), Departament de Salut, Generalitat de Catalunya, Spain, Instituto de Salud Carlos III (CIBER CB06/02/0046, RETICS RD06/0011 REM-TAP), and other local agencies and by an unrestricted educational grant from GlaxoSmithKline. The Lebanese Evaluation of the Burden of Ailments and Needs of the Nation (LEBANON) is supported by the Lebanese Ministry of Public Health, the WHO (Lebanon), National Institute of Health / Fogarty International Center (R03 WHO (Lebanon), National Institute of Health / Fogarty International Center (R03
TW006481-01), anonymous private donations to IDRAAC, Lebanon, and unrestricted grants from, Algorithm, AstraZeneca, Benta, Bella Pharma, Eli Lilly, Glaxo Smith Kline, Lundbeck, Novartis, Servier, Phenicia, UPO. The Mexican National Comorbidity Survey (MNCS) is supported by The National Institute of Psychiatry Ramon de la Fuente (INPRFMDIES 4280) and by the National Council on Science and Technology (CONACyT-G30544- H), with supplemental support from the PanAmerican Health Organization (PAHO). Te Rau Hinengaro: The New Zealand Mental Health Survey (NZMHS) is supported by the New Zealand Ministry of Health, Alcohol Advisory Council, and the Health Research Council. Zealand Ministry of Health, Alcohol Advisory Council, and the Health Research Council.
The Nigerian Survey of Mental Health and Wellbeing (NSMHW) is supported by the WHO (Geneva), the WHO (Nigeria), and the Federal Ministry of Health, Abuja, Nigeria. The Peruvian World Mental Health Study was funded by the National Institute of Health of the Ministry of Health of Peru. The Portuguese Mental Health Study was carried out by the Department of Mental Health, Faculty of Medical Sciences, NOVA University of Lisbon, Foundation, Gulbenkian Foundation, Foundation for Science and Technology (FCT) and Ministry of Health. The Romania WMH study projects 'Policies in Mental Health Area' and 'National Study regarding Mental Health and Services Use' were carried out by National School of Public Health \& Health Services Management (former National Institute for Research \& Development in Health, present National School of Public Health Management \& Professional Development, Bucharest), with technical support of Metro Media Transilvania, the National Institute of Statistics - National Centre for Training in Statistics, SC. Cheyenne Services SRL, Statistics Netherlands and were funded by Ministry of Public Health (former Ministry of Health) with supplemental support of Eli Lilly Romania SRL. The São Paulo Megacity Mental Health Survey is supported by the State of São Paulo 
Research Foundation (FAPESP) Thematic Project Grant 03/00204-3The US National Comorbidity Survey Replication (NCS-R) is supported by the National Institute of Menta Health (NIMH: U01-MH60220) with supplemental support from the National Institute of Drug Abuse (NIDA), the Substance Abuse and Mental Health Services Administration (SAMHSA), the Robert Wood Johnson Foundation (RWIF; Grant 044708), and the John W. Alden Trus J.J.M. received the John Cade Fellowship APP1056929 from the National Health and Medical Research Council, and Niels Bohr Professorship from the Danish National Research Foundation.

\section{Acknowledgements}

A complete list of all within-country and cross-national WMH publications can be found a http://www.hcp.med.harvard.edu/wmh/. We thank the staff of the WMH Data Collection and Data Analysis Coordination Centres for assistance with instrumentation, fieldwork and consultation on data analysis.

John J. McGrath, MD, PhD, Queensland Centre for Mental Health Research, and Queensland Brain Institute, University of Queensland, and National Centre for Register-based Research, Aarhus BSS, Aarhus University, Aarhus, Denmark; Sukanta Saha, PhD, Queensland Centre for Mental Health Research, and Queensland Brain Institute, University of Queensland, Australia; Carmen C. W. Lim, MSc, Queensland Brain Institute, The University of Queensland, St. Lucia, Queensland, Australia; Sergio Aguilar-Gaxiola, MD, PhD, Center for Reducing Health Disparities, UC Davis Health System, Sacramento, California, USA; Jordi Alonso, MD, PhD, Health Services Research Unit, IMIM-Hospital del Mar Medical Research Institute, Barcelona, Spain, Pompeu Fabra University (UPF), Barcelona, Spain and CIBER en Epidemiología y Salud Pública (CIBERESP), Barcelona, Spain; Laura H. Andrade, MD, PhD, Section of Psychiatric Epidemiology - LIM 23, Institute of Psychiatry, University of São Paulo Medical School, São Paulo, Brazil; Evelyn J. Bromet, PhD, Department of Psychiatry, Stony Brook University School of Medicine, Stony Brook, New York, USA; Ronny Bruffaerts, PhD, Universitair Psychiatrisch Centrum - Katholieke Universiteit Leuven (UPC-KUL), Campus Gasthuisberg, Leuven, Belgium; José M. Caldas de Almeida, MD, PhD, Chronic Diseases Research Center (CEDOC) and Department of Mental Health, Faculdade de Ciências Médicas, Universidade Nova de Lisboa, (Campo dos Mártires da Pátria), Lisbon, Portugal; Graça Cardoso, MD, PhD, Lisbon Institute of Global Mental Health and Chronic Diseases Research Center (CEDOC), Nova Medica School, Universidade Nova de Lisboa, Lisboa, Portugal; Giovanni de Girolamo, MD, Unit of Epidemiological and Evaluation Psychiatry, Istituti di Ricovero e Cura a Carattere Scientifico (IRCCS) - St. John of God Clinical Research Centre, Brescia, Italy; John Fayyad, MD, Institute for Development, Research, Advocacy \& Applied Care (IDRAAC), Beirut, Lebanon; Silvia Florescu, MD, PhD, National School of Public Health, Management and Professional Development, Bucharest, Romania; Oye Gureje, MD, DSC, FRCPsych, Department of Psychiatry, University College Hospital, Ibadan, Nigeria; Josep M. Haro, MD, PhD, Parc Sanitari Sant Joan de Déu, CIBERSAM Universitat de Barcelona, Barcelona, Spain; Norito Kawakami, MD, DMSc, Department of Mental Health, School of Public Health, The University of Tokyo, Tokyo, Japan; Karestan C. Koenen, PhD, Department of Epidemiology, Harvard T.H. Chan School of Public Health, Boston, Massachusetts, USA: Viviane Kovess-Masfety, MD, PhD, Ecole des Hautes Etudes en Santé Publique (EHESP), EA 4057 Paris Descartes University, Paris, France; Sing Lee, MBBS, Department of Psychiatry, Chinese University of Hong Kong, Tai Po, Hong Kong; Jean-Pierre Lepine, MD, Hôpital Lariboisière- Fernand Widal, Assistance Publique Hôpitaux de Paris, Universités Paris Descartes-Paris Diderot and INSERM UMR-S 1144, Paris, France; Katie A. McLaughlin, PhD, Department of Psychology, University of Washington, Seattle, Washington, USA; Maria E. Medina-Mora, PhD, National Institute of Psychiatry Ramón de la Fuente, Mexico City, Mexico; Fernando Navarro-Mateu, MD, PhD, IMIB-Arrixaca, CIBERESP-Murcia, Subdirección General de Salud Mental y Asistencia Psiquiátrica, Servicio Murciano delusional experiences Salud, El Palmar (Murcia), Spain; Akin Ojagbemi, PhD, College of Medicine, University of Ibadan; University College Hospital, Ibadan, Nigeria; Jose Posada-Villa, MD, Colegio Mayor de Cundinamarca University, Faculty of Social Sciences, Bogota, Colombia; Nancy Sampson, BA, Department of Health Care Policy, Harvard Medical School, Boston, Massachusetts, USA; Kate M. Scott, PhD, Department of Psychological Medicine, University of Otago, Dunedin, Otago, New Zealand; Hisateru Tachimori, PhD, National Institute of Mental Health, National Center for Neurology and Psychiatry, Tokyo, Japan; Margreet ten Have, PhD, Trimbos-Instituut, Netherlands Institute of Mental Health and Addiction, Netherlands; Kenneth S. Kendler, MD, Department of Psychiatry, Virginia Commonwealth University, USA; Ronald C. Kessler, PhD, Department of Health Care Policy, Harvard Medical School, Boston, Massachusetts, USA

Correspondence: John McGrath, Queensland Brain Institute, The University of Queensland, St Lucia, Queensland 4076, Australia. Email: j.mcgrath@uq.edu.au

\section{Appendix}

The WHO World Mental Health Survey collaborators are: Sergio AguilarGaxiola, MD, PhD, Ali Al-Hamzawi, MD, Mohammed Salih Al-Kaisy, MD, Jordi Alonso, MD, PhD, Laura Helena Andrade, MD, PhD, Corina Benjet, $\mathrm{PhD}$, Guilherme Borges, SCD, Evelyn J. Bromet, PhD, Ronny Bruffaerts, $\mathrm{PhD}$, Brendan Bunting, PhD, Jose Miguel Caldas de Almeida, MD, PhD, Graca Cardoso, MD, PhD, Somnath Chatterji, MD, Alfredo H. Cia, MD, Louisa Degenhardt, PhD, Koen Demyttenaere, MD, PhD, John Fayyad, MD, Silvia Florescu, MD, PhD, Giovanni de Girolamo, MD, Oye Gureje,
$M D$, DSC, FRCPsych, Josep Maria Haro, MD, PhD, Yanling He, MD, Hristo Hinkov, MD, PhD, Chi-yi Hu, MD, PhD, Yueqin Huang, MD, MPH, PhD, Peter de Jonge, PhD, Aimee Nasser Karam, PhD, Elie G. Karam, MD, Norito Kawakami, MD, DMSc, Ronald C. Kessler, PhD, Andrzej Kiejna, $\mathrm{MD}, \mathrm{PhD}$, Viviane Kovess-Masfety, MD, PhD, sing Lee, MB, BS, Jean-Pierre Lepine, MD, Daphna Levinson, PhD, John McGrath, MD, PhD, Maria Elena Medina-Mora, PhD, Jacek Moskalewicz, PhD, Fernando Navarro-Mateu, $\mathrm{MD}$, PhD, Beth-Ellen Pennell, MA, Marina Piazza, MPH, ScD, Jose Posada-Villa, MD, Kate M. Scott, PhD, Tim Slade, PhD, Juan Carlos Stagnaro, MD, PhD, Dan J. Stein, FRCPC, PhD, Margreet ten Have, PhD, Yolanda Torres, MPH, Dra. $\mathrm{HC}$, Maria Carmen Viana, MD, PhD, Harvey Whiteford, MBBS, PhD, David R. Williams, MPH, PhD, Bogdan Wojtyniak, SCD.

\section{References}

1 Trotta A, Murray RM, Fisher HL. The impact of childhood adversity on the persistence of psychotic symptoms: a systematic review and meta-analysis. Psychol Med 2015; 45: 2481-98.

2 McGrath JJ, McLaughlin KA, Saha S, Aguilar-Gaxiola S, Al-Hamzawi A, Alonso J, et al. The association between childhood adversities and subsequent first onset of psychotic experiences: a cross-national analysis of 23998 respondents from 17 countries. Psychol Med 2017; 47: 1230-45.

3 Beards S, Gayer-Anderson C, Borges S, Dewey ME, Fisher HL, Morgan C. Life events and psychosis: a review and meta-analysis. Schizophr Bull 2013; 39: 740-7.

4 Kelleher I, Harley M, Lynch F, Arseneault L, Fitzpatrick C, Cannon M Associations between childhood trauma, bullying and psychotic symptoms among a school-based adolescent sample. Br J Psychiatry 2008; 193: 378-82.

5 Spauwen J, Krabbendam L, Lieb R, Wittchen H-U, van Os J. Impact of psychological trauma on the development of psychotic symptoms: relationship with psychosis proneness. Br J Psychiatry 2006; 188: 527-33.

6 Saha S, Varghese D, Slade T, Degenhardt L, Mills K, McGrath J, et al. The association between trauma and delusional-like experiences. Psychiatry Res 2011; 189: 259-64.

7 Jenkins R, Mbatia J, Singleton N, White B. Prevalence of psychotic symptoms and their risk factors in urban Tanzania. Int J Environ Res Public Health 2010; 7: $2514-25$.

8 Scott J, Chant D, Andrews G, Martin G, McGrath J. Association between trauma exposure and delusional experiences in a large community-based sample. Br J Psychiatry 2007; 190: 339-43.

9 Kessler RC, McLaughlin KA, Koenen KC, Petukhova M, Hill ED. The importance of secondary trauma exposure for post-disaster mental disorder Epidemiol Psychiatr Sci 2012; 21: 35-45.

10 Green JG, McLaughlin KA, Berglund PA, Gruber MJ, Sampson NA, Zaslavsky AM, et al. Childhood adversities and adult psychiatric disorders in the national comorbidity survey replication I: associations with first onset of DSM-IV disorders. Arch Gen Psychiatry 2010; 67: 113-23.

11 Karam EG, Friedman MJ, Hill ED, Kessler RC, McLaughlin KA, Petukhova M, et al. Cumulative traumas and risk thresholds: 12-month PTSD in the World Mental Health (WMH) surveys. Depress Anxiety 2014; 31: 130-42.

12 McGrath JJ, Saha S, Al-Hamzawi A, Andrade L, Benjet C, Bromet EJ, et al. The bidirectional associations between psychotic experiences and DSM-IV mental disorders. Am J Psychiatry 2016; 173: 997-1006.

13 Soosay I, Silove D, Bateman-Steel C, Steel Z, Bebbington P, Jones PB, et al. Trauma exposure, PTSD and psychotic-like symptoms in post-conflict Timor Leste: an epidemiological survey. BMC Psychiatry 2012; 12: 229.

14 Kessler RC, Ustun TB. The World Mental Health (WMH) Survey Initiative Version of the World Health Organization (WHO) Composite International Diagnostic Interview (CIDI). Int J Methods Psychiatr Res 2004; 13: 93-121.

15 Kessler RC, Ustun TB. The WHO World Mental Health Surveys: Global Perspectives on the Epidemiology of Mental Disorders. Cambridge University Press, 2008.

16 American Psychiatric Association. Diagnostic and Statistical Manual of Mental Disorder (4th edn) (DSM-IV). APA, 1994

17 World Health Organization. The ICD-10 Classification of Mental and Behavioural Disorders: Clinical Descriptions and Diagnostic Guidelines. WHO, 1992.

18 Haro JM, Arbabzadeh-Bouchez S, Brugha TS, de Girolamo G, Guyer ME, Jin R, et al. Concordance of the Composite International Diagnostic Interview Version 3.0 (CIDI 3.0) with standardized clinical assessments in the WHO World Mental Health surveys. Int J Methods Psychiatr Res 2006; 15: 167-80. 
19 Benjet C, Bromet E, Karam EG, Kessler RC, McLaughlin KA, Ruscio AM, et al. The epidemiology of traumatic event exposure worldwide: results from the World Mental Health Survey Consortium. Psychol Med 2016; 46: 327-43.

20 Freedman R. Investigating trauma as a risk factor for psychosis. Schizophr Bull 2017; 43: 1-2

21 Liu H, Petukhova MV, Sampson NA, Aguilar-Gaxiola S, Alonso J, Andrade LH, et al. Association of DSM-IV posttraumatic stress disorder with traumatic experience type and history in the World Health Organization World Mental Health Surveys. JAMA Psychiatry 2017; 74: 270-81.

22 McLaughlin KA, Kubzansky LD, Dunn EC, Waldinger R, Vaillant G, Koenen KC. Childhood social environment, emotional reactivity to stress, and mood and anxiety disorders across the life course. Depress Anxiety 2010; 27: 1087-94.
23 McCrory EJ, De Brito SA, Sebastian CL, Mechelli A, Bird G, Kelly PA, et al. Heightened neural reactivity to threat in child victims of family violence. Curr Biol 2011; 21: R947-8.

24 DePrince AP, Weinzierl KM, Combs MD. Executive function performance and trauma exposure in a community sample of children. Child Abuse Negl 2009; 33: $353-61$

25 Kapur S. Psychosis as a state of aberrant salience: a framework linking biology, phenomenology, and pharmacology in schizophrenia. Am J Psychiatry 2003; 160: 13-23.

26 Barker V, Gumley A, Schwannauer M, Lawrie SM. An integrated biopsychosocial model of childhood maltreatment and psychosis. $\mathrm{Br}$ Psychiatry 2015; 206: 177-80.

\section{Kathleen Jones' Asylums and After. A Revised History of the Mental Health Services: From the Early 18th Century to the 1990s (1993)}

\section{George Ikkos}

Kathleen Jones, daughter of a lorry driver, was brought up on a council estate and won scholarships to North London Collegiate School and Westfield College, where she studied history. During WWII Westfield was relocated to Oxford, where Jones edited the oxford Socialist. She married a priest and became interested in mental health when he was appointed chaplain to a mental hospital in the 1940s. This was almost 100 years after the Lunacy Act 1845, which compelled counties to create mental asylums. By the time Asylums and After was published, Jones was a former Chair of the Association of Psychiatric Social Workers, Hon. FRCPsych and Emerita Professor and former Head of Department of Social Policy at York University.

Having been a devout member of the Church of England, Jones' attention to the facilitative role of religion in the development of the asylum system is unusual and a reason to read the book. She acknowledges great faith-based social reformers, such as the 'Clapham Set' around William Wilberforce, who developed social action policies for the Evangelical Movement, and the 7th Earl of Shaftesbury, who for almost 60 years dedicated his parliamentary career to mental health law and asylum development. The book's strongest aspect is detailed attention to parliamentary politics and the tension between central and regional authorities, as they impinge on the plight of mentally ill people.

County asylums literally transformed the landscape during the 19th century. Rising to dominate the skyline at the edge of towns and often being the largest local employer, their numbers rose from 9 in 1828 to 98 in 1930, and the number of inmates from a mere 1046 to an astonishing 119659. Even allowing for the great increase in general population during those years, a 'great confinement' (Foucault) had taken place. Jones argues that psychiatrists of the era advocated small asylums capable of generating a homely atmosphere, much like the York Retreat, but local authorities, in their search of economies of scale, drove their excessive expansion. Her moderate stance towards psychiatrists was exceptional for social scientists writing at the time. I first read Asylums and After in the second half of the 1990s, as a young consultant anxious about de-institutionalisation, and it was comforting for me at the time, though I retained some suspicion about its overall thesis.

Appearing after the Community Care Act 1990 that signalled the effective supremacy of ideologies of 'de-institutionalisation', 'normalisation' and 'advocacy' in the UK, Asylums and After was a committed defence of mental hospitals and a call for quality services for mentally ill people wherever they may be. It emerged in an intellectual landscape that was illuminated (or shadowed, depending on one's point of view) by the ideas of the 'anti-psychiatry' movement. Jones' overwhelmingly negative appraisal of the anti-psychiatrists and what she called their 'ideologies of destruction' diminishes rather than adds to the value of her book. With this caveat, one of its strengths is its focus on the influence of libertarianism on mental health from the 1960s onwards. Jones' horror is palpable when describing the Tory Minister of Health Enoch Powell, the leading libertarian politician of the time, and his famous 'water towers' speech given before an unsuspecting audience at the Annual Conference of the Association for Mental Health in 1961. Significantly, this was also the year Goffman, Foucault and Szasz published their seminal 'anti-psychiatry' works.

Experience has shown that Jones and others were right to worry about de-institutionalisation in the UK and beyond. Nevertheless, change was both morally and health-economically necessary and has made a positive difference for many. Reading Asylums and After again, I find it somewhat paternalistic and insensitive to more subtle aspects of patients' vulnerability in the face of medical authority and institutional powers. With respect to the former it pales by comparison with Roy Porter's more reflective Madness and with respect to the latter by comparison with Michel Foucault's controversial but ground-breaking History of Madness. Together, the three offer a most lively and balanced introduction to the social history of psychiatry. 